\title{
Construction of Fingerprint for Michelia Germplasm by Fluorescent SSR Markers
}

He Xudong】, Jiao Zhongyi, Zheng Jiwei, Dou Quanqin, Huang Libin, Wang Baosong, Huang Ruifang

Jiangsu Academy of Forestry, Nanjing, 211153, China

DCorresponding author Email: hxd 519@163.com

Molecular Plant Breeding, 2019, Vol.10, No.7 doi: $\underline{10.5376 / \mathrm{mpb} .2019 .010 .0007}$

Received: 08 Oct., 2018

Accepted: 24 Apr., 2019

Published: 23 May, 2019

Copyright $\odot 2019$ He et al., This article was first published in Molecular Plant Breeding (2018, 16(14): 4705-4714) in Chinese, and here was authorized to translate and publish the paper in English under the terms of Creative Commons Attribution License, which permits unrestricted use, distribution, and reproduction in any medium, provided the original work is properly cited.

Preferred citation for this article:

He X.D., Jiao Z.Y., Zheng J.W., Dou Q.Q., Huang L.B., Wang B.S., and Huang R.F., 2019, Construction of fingerprint for Michelia germplasm by fluorescent SSR markers, Molecular Plant Breeding, 10(7): 50-58 (doi: 10.5376/mpb.2019.010.0007)

\begin{abstract}
In this study, a fingerprinting system for 16 Michelia germplasms was established using high-throughput genotyping of fluorescent simple sequence repeat (SSR) markers. In total, 102 alleles were detected using 13 pairs of SSR markers from closely related species, and the number of alleles per locus ranged from 5 to 11, with an average of 7.8 alleles. Observed heterozygosity (Ho), expected heterozygosity (He), and polymorphic information content (PIC) ranged from 0.1250 to 0.5625 (mean 0.3650 ), 0.6703 to 0.9113 (mean 0.8099), and 0.5748 to 0.8714 (mean 0.7515), respectively. Among the four selected core primer pairs, the combinations LT106 and SGA5, LT106 and LT58, and SGA5 and MMA51 could unambiguously distinguish 16 Michelia germplasms. A cluster analysis showed the similarity coefficient of the 16 Michelia germplasms to range from 0.70 to 0.90 , and different individuals from the same species clustered in the same branch. The fluorescence SSR genotyping system established in this study was efficient, rapid, and accurate; moreover, this approach provides a theoretical basis for identifying germplasms and for the protection of new varieties of the genus Michelia, and it provides a robust foundation for further breeding development of Michelia sp.
\end{abstract}

Keywords Michelia, Fluorescent marker, SSR, Fingerprint

The Magnoliaceae are one of the oldest angiosperm families and comprise various important flowering plants. The taxonomic and phylogenetic relationships of numerous Magnoliaceae species has been disputed due to the similarity of morphological characteristics and tissue structures, and particularly the division of genera has been an issue of disagreement (Sun and Zhou, 2004; Meng et al., 2006). The genus Michelia is the second largest genus of the Magnoliaceae and comprises more than 40 species indigenous to China, the phenotypes of which are considerably variable within and between species, e.g., M. maudiae (Chen et al., 2016) and M. crassipes (Wen et al., 2014). A phylogenetic classification of Michelia was the main focus of the study of Zhang (2007). Moreover, hybridization of various Michelia species is easily achieved owing to their close relationships and lack of reproductive isolation; furthermore, phenotypic variations may occur due to environmental factors, which further complicates the unambiguous identification of species (Fowler et al., 1988). Therefore, novel DNA sequence-based approaches are needed for a reliable classification of Michelia on species level.

Most trees of the genus Michelia are evergreen, show an attractive growth habit, and produce a pleasant scent, which made these trees popular for urban landscaping; furthermore, Michelia trees have been used as a raw material in the wood industry and for the production of medicine and oil (Ye et al., 2013). In recent years, numerous new varieties of Michelia have been produced following a rapid development of breeding programs in China; these new varieties include 'Yujin', 'Danxin' and 'Qinfang' (Gong et al., 2003a), 'Chuju', 'Chunyue' (Gong et al., 2003b), 'Mozi' (Liao et al., 2007), 'Wanchun' (Mao et al., 2009), 'Huahaoyueyuan' (Liu et al., 2014), 'Chunyun', 'Yuxia' (Central South University of Forestry and Technology), and 'Jinxiu' (Huang et al., 2016). However, because of the morphological similarities between varieties of Michelia, frequent introduction of new varieties in production systems inevitably causes undesired hybridization. Homonymies and synonymies may occur from time to time, and even variety fraud has occurred to achieve commercial advantages. This further 
complicates the evaluation of genetic resources, variety selection, and popularization of Michelia varieties. At the same time, in view of the need for the legal protection of new plant varieties, a robust, efficient, and reliable molecular marker identification system is required, which will contribute to the protection of commercially registered varieties and can ensure further development of the Michelia planting industry in China.

The molecular marker technology is based on DNA and cannot be affected by the environment; moreover, this approach which is simple, efficient, and provides accurate and reliable results, has been widely used in various fields of genetics and genomics. Among molecular markers, simple sequence repeats (SSR) have been proven considerably useful as genetic markers owing to substantial genome coverage, hyper-variability, co-dominant inheritance, high interspecies transferability, and good reproducibility (Kalia et al., 2011). This approach has been successfully applied for phylogenetic analyses and germplasm identification of several woody species, e.g., Populus sp. (Jia et al., 2015; Liu et al., 2016; Ou et al., 2017), Eucalyptus sp. (Li et al., 2011), Pinus massoniana (Shen et al., 2015), Ginkgo biloba (Wang et al., 2017), Camellia oleifera (Zhou et al., 2017), Amygdalus persica (Wang et al., 2016), Osmanthus fragrans (Duan et al., 2014), Tamarix chinensis (Ye et al., 2015), and Litchi chinensis (Madhou et al., 2013). However, the molecular biological study of Michelia in China commenced relatively late, and only one scientific report has been published so far (Wen et al., 2014). Therefore, EST-SSR primers for M. maudiae and Liriodendron tulipifera were chosen and screened for interspecies transferability and detection of polymorphisms, which were subsequently labeled using fluorescent probe and used to establish a fingerprinting system for 16 Michelia germplasms. The objective of our study was to establish an efficient, rapid, and accurate genotyping system for the genus Michelia, to provide a scientific theoretical basis for the identification of germplasm resources and for the legal protection of new varieties, and to provide reference for future breeding of Michelia.

\section{Results and Analyses}

\subsection{Cross-species amplification}

A set of 34 SSR primer pairs was selected to evaluate interspecific transferability in eight Michelia species: $M$. chapensis, M. maudiae, M. Jinxiu, M. wilsonii, M. foveolata, M. platypetala, M. compressa, and M. macclurei. Out of ten primer pairs for M. mandiae, only one primer pair failed to show amplification from M. platypetala samples, whereas the other nine primer pairs showed successful amplification from samples of all eight species, which indicated high interspecific transferability. Using the 24 L. tulipifera primer pairs, amplification efficiency ranged from $21 \%$ in $M$. wilsonii and M. macclurei to $38 \%$ in M. maudiae (Table 1). Therefore, nine primer pairs of M. maudiae and four primer pairs of L. tulipifera were selected and labeled with fluorescent probes for Michelia genotyping and fingerprinting.

\subsection{Polymorphism evaluation}

A total of 13 EST-SSRs were used to assess polymorphisms in 16 Michelia germplasms, which produced 102 alleles, and the number of alleles per locus ranged from 5 to 11 with an average of 4.8 alleles. The highest number of alleles $(\mathrm{n}=11)$ was amplified using SGA5, MMA72, and LT106, and the lowest number $(\mathrm{n}=5)$ was produced using

Table 1 Cross-species amplification of the 34 SSR primers

\begin{tabular}{|c|c|c|c|c|c|}
\hline \multirow{2}{*}{ Species } & \multicolumn{2}{|c|}{10 Primers from Michelia } & \multicolumn{2}{|c|}{24 Primers from Liriodendron } & \multirow{2}{*}{-Total } \\
\hline & No. of successful & Percentage & No. of successful & Percentage & \\
\hline M. chapensis & 10 & $100 \%$ & 8 & $33 \%$ & 18 \\
\hline M. maudiae & 10 & $100 \%$ & 9 & $38 \%$ & 19 \\
\hline M. maudiae 'jinxiu' & 10 & $100 \%$ & 7 & $29 \%$ & 17 \\
\hline M. wilsonii & 10 & $100 \%$ & 5 & $21 \%$ & 15 \\
\hline M. foveolata & 10 & $100 \%$ & 8 & $33 \%$ & 18 \\
\hline M. platypetala & 9 & $90 \%$ & 6 & $25 \%$ & 15 \\
\hline M. compressa & 10 & $100 \%$ & 6 & $25 \%$ & 16 \\
\hline M. macclueei & 10 & $100 \%$ & 5 & $21 \%$ & 15 \\
\hline
\end{tabular}


SGA15, MMA19, LT47, and LT186. Observed heterozygosity (Ho) ranged from 0.1250 to 0.5625 , with an average of 0.3650 , and expected heterozygosity (He) ranged from 0.6703 to 0.9113 , with an average of 0.8099 . Polymorphic information content (PIC) varied from 0.5748 to 0.8714 , with an average of 0.7515 . The highest PIC (0.8714) was produced using SGA5 and the lowest PIC (0.5748) was produced using LT186 (Table 2). Partial genotyping markers of Michelia germplasms using SGA5 is shown in Figure 1.

\subsection{Fingerprinting of Michelia}

Four core primer pairs were selected from 13 SSR primer pairs to establish a fingerprinting system for Michelia germplasms by further analyzing the allelic fragments of each locus (Table 3). Ten Michelia germplasms could be distinguished using the primer pair LT106, and eight Michelia germplasm could be distinguished using the primer pair SGA5. All 16 Michelia germplasms could be identified using a combination of the primers LT106 and SGA5 or a combination of the primers LT106 and LT58, or SGA5 and MMA51. Therefore, the four selected core primer pairs can be used to distinguish the germplasms examined here and also for reciprocal validation by using different combinations of primers.

Table 2 Polymorphisms of the thirteen SSRs in 16 individuals of Michelia

\begin{tabular}{llllll}
\hline Locus & No. of allele & Length of allele & $H_{o}$ & $H_{e}$ & PIC \\
\hline SGA5 & 11 & $209-247$ & 0.4375 & 0.9113 & 0.8714 \\
SGA15 & 5 & $157-183$ & 0.1250 & 0.7036 & 0.6271 \\
MMA10 & 8 & $189-221$ & 0.1875 & 0.8367 & 0.7868 \\
MMA19 & 5 & $201-229$ & 0.4667 & 0.7471 & 0.6706 \\
MMA36 & 10 & $268-294$ & 0.2000 & 0.9011 & 0.8577 \\
MMA37 & 9 & $206-238$ & 0.5000 & 0.8768 & 0.8215 \\
MMA51 & 8 & $298-330$ & 0.5625 & 0.8427 & 0.7926 \\
MMA67 & 8 & $138-156$ & 0.3750 & 0.6976 & 0.6371 \\
MMA72 & 11 & $210-250$ & 0.2000 & 0.8782 & 0.8331 \\
LT47 & 5 & $276-310$ & 0.4615 & 0.8000 & 0.7312 \\
LT58 & 6 & $217-236$ & 0.5000 & 0.7540 & 0.6970 \\
LT106 & 11 & $276-310$ & 0.5625 & 0.9093 & 0.8692 \\
LT186 & 5 & $227-303$ & 0.1667 & 0.6703 & 0.5748 \\
Total & 102 & & & & 0.7515 \\
Mean & 7.8 & & 0.3650 & 0.8099 & \\
\hline
\end{tabular}
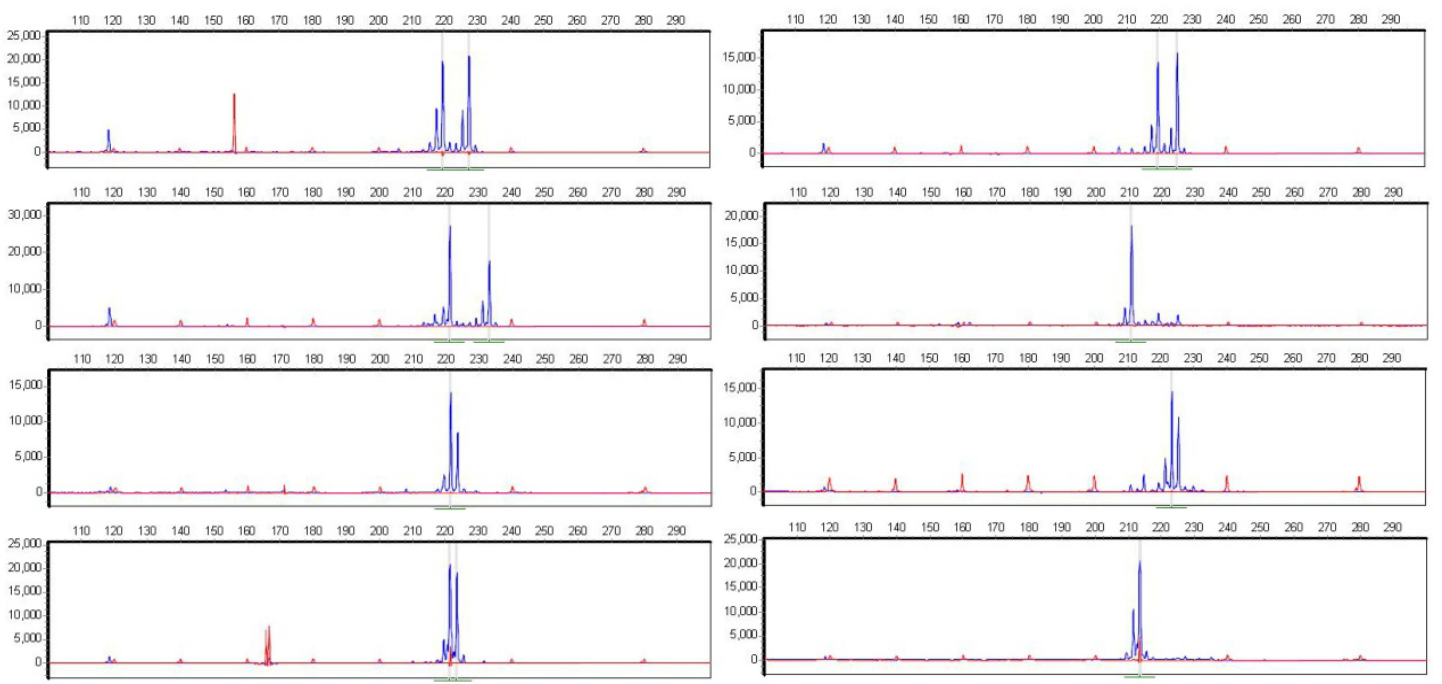

Figure 1 Genotyping by SGA5 marker for partial Michelia germplasms 
Molecular Plant Breeding 2019, Vol.10, No.7, 50-58

http://genbreedpublisher.com/index.php/mpb

Table 3 Fingerprint map of 16 materials of Michelia

\begin{tabular}{lllll}
\hline Individuals & Core Primer & & & LT106 \\
\cline { 2 - 4 } & SGA5 & MMA51 & LT58 & 308 \\
\hline M. chapensis-1 & $219 / 227$ & $298 / 324$ & $221 / 233$ & $298 / 310$ \\
M. chapensis -2 & 213 & $324 / 330$ & 221 & $296 / 308$ \\
M. chapensis -3 & $219 / 227$ & 326 & $221 / 233$ & $296 / 308$ \\
M. chapensis -4 & 219 & 326 & $221 / 230$ & 298 \\
M. chapensis -5 & 211 & 326 & 221 & 278 \\
M. maudiae-1 & $221 / 233$ & $298 / 304$ & 230 & $286 / 300$ \\
M. maudiae-2 & 221 & $298 / 300$ & $230 / 236$ & 280 \\
M. maudiae-3 & $219 / 225$ & $298 / 300$ & 230 & $276 / 280$ \\
M. maudiae-4 & 209 & $298 / 300$ & 230 & 286 \\
M. maudiae-5 & $221 / 223$ & $298 / 300$ & $230 / 236$ & 280 \\
M. maudiae 'Jinxiu' & $219 / 225$ & $300 / 324$ & $230 / 236$ & $286 / 294$ \\
M. wilsonii & 211 & 306 & 227 & $286 / 294$ \\
M. foveolata & 223 & 320 & $224 / 230$ & 294 \\
M. platypetala & $231 / 247$ & 298 & $227 / 230$ & 282 \\
M. compressa & 213 & 300 & 224 & 230 \\
M. macclueei & 225 & $298 / 304$ & & \\
\hline
\end{tabular}

\subsection{Cluster analysis}

Genetic similarity coefficients were calculated and clustered based on UPGMA using the 13 fluorescently amplified SSR markers (Figure 2). The genetic similarity coefficient of 16 Michelia germplasms varied from 0.70 to 0.90 , and a similarity coefficient of 0.77 produced five groups.

Group I consisted of five individuals (1, 2, 3, 4, and 5), all of which were $M$. chapensis. Individuals 3 and 4 were most closely related and produced the highest genetic similarity coefficient (0.90). Individual 2 was slightly divergent from the other four individuals. Group II included M. wilsonii (12), M. compressa (15), and $M$. macclurei (16). Group III comprised five M. maudiae individuals (6-10) and one M. maudiae cv. Jinxiu individual (11). However, the variety 'Jinxiu' was a superior individual originating from a natural variation of M. maudiae. Group IV comprised only M. platypetala (14), which was closely related to M. maudiae. Group V contained M. foveolata (13), which was most divergent from all other individuals.

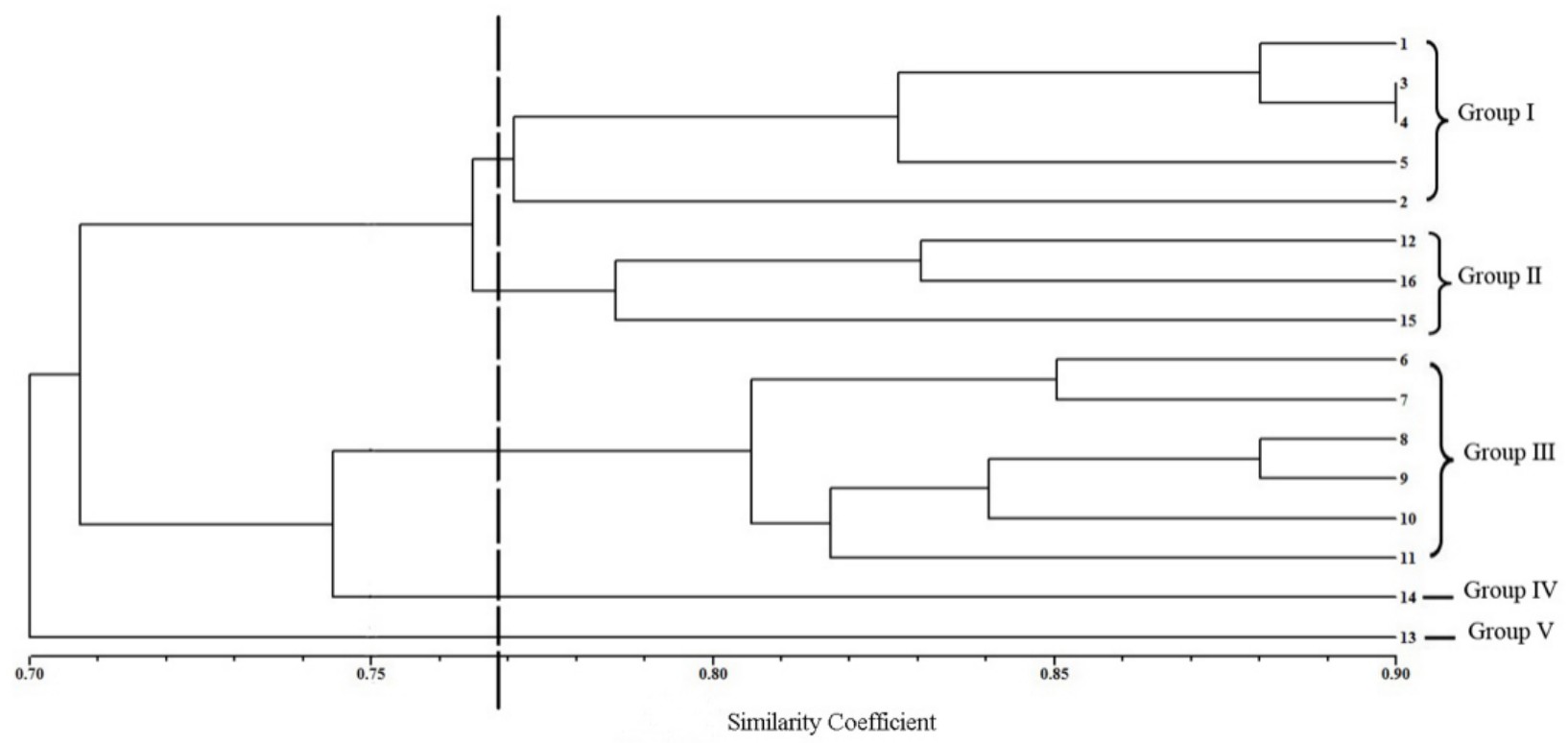

Figure 2 Dendrogram of 16 Michelia individuals based on SSR data 


\section{Discussion}

SSR markers are widely distributed in eukaryotic and prokaryote genomes. Compared with genomic SSR, EST-SSR markers located in a transcription region are typically less polymorphic than genomic SSR (He, 2010), therefore they tend to be more conserved and thus are more compatible between species (Xu et al., 2006; Yadav et al., 2011), genera (Yadav et al., 2011; Li and Sun, 2012), and families (Decroocq et al., 2003). A fingerprinting system for 16 Michelia germplasms was successfully established using EST-SSR markers of M. maudiae and $L$. tulipifera. In this study, the transferability of EST-SSRs of Liriodendron and Michelia was 21-38\%, which was lower than that observed by Li et al. (2011; 24-71\%) and lower than that of Liriodendron and Magnolia (54\%). However, the transferability of EST-SSRs is generally affected by the proportion of conserved SSR-flanking sequences (Cordeiro et al., 2001), the position of the primer sequences in the EST (Li et al., 2011), genome size, life span, and the type of mating system (Ueno et al., 2009).

Unlike traditionally used marker such as RAPD, ISSR, and AFLP, SSRs are co-dominant, which means that homozygous or heterozygous loci can be distinguished and the complete genetic information can be extracted (Song et al, 2012). Moreover, owing to hyper-variability, closely related species and even hybrid progeny can be accurately identified. For example, in species related to Osmanthus fragrans (Duan et al., 2014), Populus (Jia et al., 2015), Ginkgo biloba (Wang et al., 2017), or Camellia sinensis (Chen et al., 2017), and in hybrid progeny of Juglans regia (Pollegioni et al., 2009), Ziziphus jujuba (Sun et al., 2015), Myrica rubra (Wang et al., 2015) and other woody plants, fingerprinting systems were successfully established using SSR markers. Compared with traditional high-resolution agarose gel electrophoresis and polyacrylamide gel electrophoresis, the technique of fluorescence SSR capillary electrophoresis genotyping based on high-throughput sequencing are easy to use, less time consuming, highly efficient, cost-effective, highly accurate and reproducible (Liesebach et al., 2010; Fariaet al., 2011). To test large numbers of individuals, multiple PCRs can be employed to save costs and increase throughput (Drašnarová et al., 2014; Wu et al., 2016). The fingerprinting system established in this study may help distinguish eight closely related species by using different primer combinations and can also be used to identify different individuals of M. chapensis and M. maudiaespecies, emphasizing the high efficiency and accuracy of SSR markers.

The classification of genera and species of the Magnoliaceae has traditionally been an issue of disagreement, including the phylogenetic classification of Michelia (Zhang, 2007). The phylogenetic history and divergence of the genus Michelia has been widely discussed, and at present, there are two taxonomic systems, one suggested by Liu et al. (1996) and the other by Chen and Nooteboom (1993). In the current study, eight species of Michelia were assigned to five groups. In line with Li $(2008 ; 2013)$, group I (containing five $M$. chapensis individuals) and group II (M. wilsonii, M. compressa and M. macclurei) formed a branch, which indicated that M. chapensis was closely related to the other three species. Group III consisted of five M. maudiae individuals and one M. maudiae cv. Jinxiu individual, which also suggested that Michelia 'Jinxiu' was a superior individual originating from a natural variation of M. maudiae. The groups IV and V were M. foveolata and M. platypetala, respectively, indicating considerably divergent phylogeny from other species, whereas Wen et al. (2014) suggested $M$. platypetala and M. maudiae to be closely related; however, M. maudiae and M. chapensis formed two separate branches in their study, which is in line with our results. The phenotypes of numerous Michelia species vary depending on their habitat, including M. foveolata (Zhang, 2007), and a different number or type of markers and different sample numbers may also lead to discrepancies in taxonomic classifications. Therefore, in order to accurately classify the genus Michelia, multiple criteria such as morphology, cytology, and molecular biology should be applied.

\section{Materials and Methods}

\subsection{Plant material and DNA isolation}

A total of 16 individuals of Michelia, including five M. chapensis, five M. maudiae, one 'Jinxiu' Michelia, one M. wilsonii, one $M$. foveolata, one M. platypetala, one M. compressa, and one M. macclurei were selected from a 
Michelia nursery at the Jiangsu Academy of Forestry (Nanjing, Jiangsu Province. China; Table 4). From each individual, young leaves were collected, immediately frozen using liquid nitrogen, and stored at $-70^{\circ} \mathrm{C}$. A commercially available plant DNA extraction kit (DP305; Tiangen Biochemistry Technology Co. Ltd, Beijing) was used to isolate total DNA, according to the manufacturer's instructions. DNA integrity was assessed by $0.8 \%$ agarose gel electrophoresis. Purity and DNA concentration were determined using a UV spectrophotometer, and the samples were stored at $-20^{\circ} \mathrm{C}$.

\subsection{Primer screening and transferability detection}

Out of 49 SSR markers derived from M. maudiae (Sun et al., 2010) and L. tulipifera (Yang et al., 2012), 34 markers with high transferability were selected for cross-species amplification. Genomic DNA of individuals 1, 6, $11,12,13,14,15$, and 16 was used as templates for preliminary primer screening after which 13 SSR markers were selected for fingerprinting (Table 5). All markers were labeled with fluorescent groups at the 5' end as mentioned above and were synthesized by Shanghai Lingen Biotechnology Co., Ltd.

PCR reactions of $10 \mu \mathrm{L}$ contained $5 \mu \mathrm{L}$ PCR mix, $3.4 \mu \mathrm{L} \mathrm{ddH}_{2} \mathrm{O}, 0.3 \mu \mathrm{L}$ forward primer, $0.3 \mu \mathrm{L}$ reverse primer, and about $1 \mu \mathrm{L}$ DNA template. The reaction was performed using the following thermocycling program: $94{ }^{\circ} \mathrm{C}$ for $5 \mathrm{~min}$, followed by 35 cycles of $94{ }^{\circ} \mathrm{C}$ for $50 \mathrm{~s}, 56^{\circ} \mathrm{C}$ for $50 \mathrm{~s}$, and $72{ }^{\circ} \mathrm{C}$ for $90 \mathrm{~s}$, and a final extension step at $72{ }^{\circ} \mathrm{C}$ for $7 \mathrm{~min}$. PCR products were visualized by electrophoresis using $1.5 \%$ agarose gels.

\subsection{Genotyping system establishment}

The PCR reaction volume for genotyping was $15 \mu \mathrm{L}$ (Table 6). The reaction was performed under the following thermocycling conditions: $94{ }^{\circ} \mathrm{C}$ for 3 min, followed by 35 cycles of $94{ }^{\circ} \mathrm{C}$ for $15 \mathrm{~s}, 55{ }^{\circ} \mathrm{C}$ for $15 \mathrm{~s}$, and $72{ }^{\circ} \mathrm{C}$ for $30 \mathrm{~s}$, and a final extension step at $72{ }^{\circ} \mathrm{C}$ for $3 \mathrm{~min}$. The PCR products were visualized by agarose gel electrophoresis; after this, the products were diluted 10-fold and mixed with the internal standard of ROX 500. The denaturation reactions of a volume of $10 \mu \mathrm{L}$ contained $8.25 \mu \mathrm{L}$ HiDi, $0.25 \mu \mathrm{L}$ ROX 500, and $1.5 \mu \mathrm{L}$ diluted PCR product. After $5 \mathrm{~min}$ of denaturation at $95{ }^{\circ} \mathrm{C}$, the reaction was immediately placed on ice for 3 min and then sequenced using an ABI 3730xl DNA Analyzer (Applied Biosystems, Foster City, CA), according to the manufacturer's instructions.

\subsection{Data analyses}

The number of alleles (Na), He, Ho, and PIC were calculated for each EST-SSR locus using MSA software.

Table 4 Experimental materials

\begin{tabular}{lll}
\hline Individuals code & Species & Collection sites \\
\hline 1 & M. chapensis-1 & \\
2 & M. chapensis -2 & \\
3 & M. chapensis -3 & \\
4 & M. chapensis -4 & \\
5 & M. chapensis -5 & \\
6 & M. maudiae-1 & \\
7 & M. maudiae-2 & \\
8 & M. maudiae-3 & \\
9 & M. maudiae-4 & \\
10 & M. maudiae-5 & \\
11 & M. maudiae 'Jinxiu' & \\
12 & M. wilsonii \\
13 & M. foveolata & \\
14 & M. platypetala & \\
15 & M. compressa & \\
16 & Macclueei &
\end{tabular}


Molecular Plant Breeding 2019, Vol.10, No.7, 50-58

$\mathrm{http}: / /$ genbreedpublisher.com/index.php/mpb

Table 5 Details of 13 SSR primers

\begin{tabular}{|c|c|c|c|c|}
\hline Code & Name & Primer sequence & Motif & Expectation fragment (bp) \\
\hline \multirow{2}{*}{1} & \multirow{2}{*}{ SGA5 } & F: GAGATGAGTCACCGCCTGTT & \multirow{2}{*}{$(\mathrm{AG})_{15}$} & \multirow{2}{*}{234} \\
\hline & & R: ATTCAGTTGCACGGCTCTCT & & \\
\hline \multirow{2}{*}{2} & \multirow{2}{*}{ SGA15 } & F: CTGACGTAACCCGACCTGAT & \multirow{2}{*}{$(\mathrm{GA})_{14}$} & \multirow{2}{*}{171} \\
\hline & & R: CCTGACTTGATCCCACCACT & & \\
\hline \multirow{2}{*}{3} & \multirow{2}{*}{ MMA10 } & F: TCСАССССТTТСТСТССТTТ & \multirow{2}{*}{$(\mathrm{TC})_{10}$} & \multirow{2}{*}{197} \\
\hline & & R: AGCCTCCGGATGAGTCCTAT & & \\
\hline \multirow{2}{*}{4} & \multirow{2}{*}{ MMA19 } & F: GAAATTGGAGAAATCGACTG & \multirow{2}{*}{$(\mathrm{AG})_{6} \ldots(\mathrm{AG})_{5}$} & \multirow{2}{*}{211} \\
\hline & & R: CССТCTCTTACGCCTCTC & & \\
\hline \multirow{2}{*}{5} & \multirow{2}{*}{ MMA36 } & F: CAATATGGGTTCTTCGGGTTT & \multirow{2}{*}{$(\mathrm{AG})_{12}$} & \multirow{2}{*}{260} \\
\hline & & R: TCCACACTGGTTTTTGGTGA & & \\
\hline \multirow{2}{*}{6} & \multirow{2}{*}{ MMA37 } & F: TAGGATGGTCCCACCTTGTT & \multirow{2}{*}{$(\mathrm{TC})_{18}$} & \multirow{2}{*}{222} \\
\hline & & R: CAAAACCGTTGAGGCAAAAC & & \\
\hline \multirow{2}{*}{7} & \multirow{2}{*}{ MMA51 } & F: CGATGCAGCCTAAAAAGAGC & \multirow{2}{*}{$(\mathrm{GA})_{10}$} & \multirow{2}{*}{298} \\
\hline & & R: CGATCATCTCTCCCGTCACT & & \\
\hline \multirow{2}{*}{8} & \multirow{2}{*}{ MMA67 } & F: CACGAATCCAAGGAAAGGAA & \multirow{2}{*}{$(\mathrm{TC})_{8}$} & \multirow{2}{*}{147} \\
\hline & & R: CGTCCGTCTCAGAACCTCTC & & \\
\hline \multirow{2}{*}{9} & MMA72 & F: TTTTCCACCCCTCTCGAATA & $(\mathrm{GA})_{14}$ & 222 \\
\hline & IVIVIA & R: CCATTATGCTGGGGTGTCTT & (UA) 14 & 222 \\
\hline 10 & IT47 & F: TCCATCCCTATCTCTGCCAT & (TG) & 278 \\
\hline 10 & 2141 & R: GGCGTTTGTCCATGTTTGTA & $(10) 13$ & 210 \\
\hline 11 & LT58 & F: GTACTGCCATCAAGGCCAAT & $(\mathrm{CTT})_{10}$ & 236 \\
\hline 11 & & R: CAACACTTTCGCATGCAACT & (C11010 & 250 \\
\hline 12 & LT106 & F: ATGCAGTGGCCATACATCAG & $(\mathrm{CT})_{17}$ & 237 \\
\hline 12 & Litov & R: GCACAGCAGAACAAAGGTCA & (C1)17 & \\
\hline 13 & LT186 & F: TGCCCACATGTGCTATGTTT & $\left(\mathrm{GA}_{17}\right.$ & 241 \\
\hline & & R: CCAACCCAACTGCTTTTGTT & $(\mathrm{OA}) 17$ & 241 \\
\hline
\end{tabular}

Table 6 PCR reaction system for genotyping

\begin{tabular}{lll}
\hline Code & Item & Volume \\
\hline 1 & $\mathrm{MgCl}_{2}(25 \mathrm{mmol} / \mathrm{L})$ & $1.5 \mu \mathrm{L}$ \\
2 & DNA & $1 \mu \mathrm{L}$ \\
3 & $10 \times$ buffer & $1.5 \mu \mathrm{L}$ \\
4 & Forward Primer & $0.15 \mu \mathrm{L}$ \\
5 & Reverse Primer & $0.15 \mu \mathrm{L}$ \\
6 & DNTP $(10$ mmol $/ \mathrm{L})$ & $0.3 \mu \mathrm{L}$ \\
7 & Taq Polymerase $(5 \mathrm{u} / \mu \mathrm{L})$ & $0.3 \mu \mathrm{L}$ \\
8 & ddH $\mathrm{O}_{2} \mathrm{O}$ & $10.1 \mu \mathrm{L}$ \\
9 & Total & $15 \mu \mathrm{L}$ \\
\hline
\end{tabular}

Alleles were transformed to a $0 / 1$ matrix according to the fragments, and SM similarity coefficients were calculated. The software NTSYS-pcversion 2.1 was used to cluster the 16 individuals of Michelia using a UPGMA method.

\section{Authors' Contributions}

JZY and ZJW designed and performed the experiments of this study. ZJW analyzed the data. DQQ and HLB participated in the experiment design and data analyses. HXD conceived this study and supervised experimental design, data analyses, manuscript writing, and revisions. All authors read and approved the final manuscript.

\section{Funding information}

This work was financially supported by the Fund for promotion and demonstration of forestry science and technology in 
central finance (No. su[2017]TG03).

\section{References}

Chen B.L., and Nooteboom H.P., 1993, Notes on MagnoliaceaeIII: the magnoliaceae of China, Ann. MoBot. Gard., 80(4): 999-1104 https://doi.org/10.2307/2399942

Chen Q.E., Sima Y.K., Hao J.B., Xu L., and Wu S.B., 2016, Floral variation of Michelia maudiae and endemic ornamental tree endemic in China, Hubei Nongye Kexue (Hubei Agricultural Sciences), 55(8): 2023-2030

Chen S.J., Zhang M.Z., Yao Y.X., and Xie W.B., 2017, Establishment of DNA fingerprinting for tea germplasm from Qiannan prefecture by SSR markers, Zhiwu Yichuan Ziyuan Xuebao (Journal of Plant Genetic Resources), 18(1): 106-111

Cordeiro G.M., Casu R., Mcintyre C.L., Manners J.M., and Henry R.J., 2001, Microsatellite markers from sugarcane (Saccharum spp.) ESTs cross transferable to erianthus and sorghum, Plant Sci., 160(6): 1115-1123 https://doi.org/10.1016/S0168-9452(01)00365-X

Decroocq V., Fave M.G., Hagen L., Bordenave L., and Decroocq S., 2003, Development and transferabilit y of apricot and grape EST microsatellite markers across taxa, Theor. Appl. Genet., 106(5): 912-922

https://doi.org/10.1007/s00122-002-1158-Z PMid: 12647067

Drašnarová J., Krak K., Vít P., Doudová J., Douda J., Hadincová V., Zákravský P., and Mandák B., 2014, Cross-amplification and multiplexing of SSR markers for Alnus glutinosa and A. incana, Tree Genet. Genomes, 10(4): 865-873 https://doi.org/10.1007/s11295-014-0727-Z

Duan Y.F., Wang X.R., Liang L.L., Li X.X., and Xiang Q.B., 2014, Fingerprinting and identification of Osmanthus fragrans cultivars using fluorescence-labeled SSR markers, Nanjing Linye Daxue Xuebao (Journal of Nanjing ForestryUniversity), 38(S): 1-6 https://doi.org/10.3732/apps.1200092 PMid:25202550 PMCid:PMC4105023

Faria D.A., Mamani E.M.C., Jr G.J.P., and Grattapaglia D., 2011, Genotyping systems for Eucalyptus based on tetra-, penta-, and hexanucleotide repeat EST microsatellites and their use for individual fingerprinting and assignment tests, Tree Genet. Genomes, 7(1): 63-77 https://doi.org/10.1007/s11295-010-0315-9

Fowler D.P., Park Y.S., and Gordon A.G., 1988, Genetic variation of red spruce in the Maritimes, Can. J. Forest Res., 18 (6): $703-709$ https://doi.org/10.1139/X88-107

Gong X., Zhang G.L., Pan Y.Z., and Yang Z.Y., 2003a, Three new varieties of Michelia, Yuanyi Xuebao (Acta Horticulturae Sinica), $30(1)$ : 123

Gong X., Zhang G.L., Pan Y.Z., and Yang Z.Y., 2003b, Two new hybrid varieties of Michelia, Yuanyi Xuebao (Acta Horticulturae Sinica), 30 (2): 251

He X.D., 2010, Heterosis on Eucalyptus hybrids and molecular marker-assisted selection, Dissertation for Ph.D., Nanjing Forestry University, Supervisor: Shi J.S., pp.64-68

Huang L.B., Dou Q.Q., Dong X.Y., Zhang M., and Li X.C., 2016, A new variety of Michelia maudiae 'Jinxiu', Linye Kexue (Scientia Silvae Sinicae), 52 (9): 154

Jia H.X., Ji H.J., Hu J.J., and Lu M.Z., 2015, Fingerprints of SSR markers and ploidy detection for new Populus varieties, Linye Kexue (Scientia Silvae Sinicae), 51 (2): 69-79

Kalia R.K., Rai M.K., Kalia S., Singh R., and Dhawan A.D., 2011, Microsatellite markers: an overview of the recent progress in plants, Euphytica, 177(3): 309-334 https://doi.org/10.1007/s10681-010-0286-9

Li C., and Sun Y., 2012, Transferability analysis of EST-SSR markers of Castanea mollissima to Castanopsis fargesii, Guangxi Zhiwu (Guihaia), 32(3): 293-297

Li F.G., Gan S.M., Zhang Z.Y., Weng Q.J., Xiang D.Y., and Li M., 2011, Microsatellite-based genotyping of the commercial Eucalyptus clones cultivated in China, Silvae Genet., 60 (5): 216-223 https://doi.org/10.1515/sg-2011-0029

Li H.Y., 2008, The cross-genus transferability of EST-SSR from Liriodendron tulipifera Linn. and the implications for the phylogeny of Magnolicaceae, Thesis for M.S., Nanjing Forestry University, Supervisor: Li H.G., pp.36-42

Li H.Y., Li K.Q., Xu M., and Li H.G., 2011, Cross-genus transferability of EST-SSR markers from Liriodendron tulipifera of Magnoliaceae, Dongbei Linye Daxue Xuebao (Journal of Northeast Forestry University), 39(2): 28-30, 42

Li J., Jin X.D., Yang Q.S., Pei H.C., and Liu Z.X., 2013, AFLP and ISSR markers analysis of the genetic relationship of 7 kinds of Magnoliaceae evergreen plants, Henan Nongye Daxue Xuebao (Journal of Henan Agricultural University), 47(3): 289-29

Liao J.Y., 2007, Selective breeding of new cultivars for the Michelia crassipes Law, Xibei Linxueyuan Xuebao (Journal of Northwest Forestry University), 22(2): $76-78$

Liesebach H., Schneck V., and Ewald E., 2010, Clonal fingerprinting in the genus Populus L. by nuclear microsatellite loci regarding differences between sections, species and hybrids, Tree Genet.Genomes, 6(2): 259-269

https://doi.org/10.1007/s11295-009-0246-5

Liu J., Jiang J.M., Yao Y.D., and Jiang A.P., 2014, A new variety of Michelia 'Huahaoyueyuan', Linye Kexue (Scientia Silvae Sinicae), 50(12): 169

Liu J.X., Song X.Y., Jiang W.H., Zhou G.N., and Gao B.J., 2016, SSR analysis on stress effect of transgenic hybrid poplar 741 on Clostera anachoreta (Fabricius) (Lepidoptera: Notodontidae), Yingyong Shengtai Xuebao (Chinese Journal of Applied Ecology), 27(12): 4039-4044

Liu Y.H., Luo X.R., and Wu R.F., eds., 1996, Flora Reipublicae Popularis Sinicae 30(1), Science Press, Beijing, China, pp.151-191 
Madhou M., Normand F., Bahorun J., and Hormaza I., 2013, Fingerprinting and analysis of genetic diversity of litchi (Litchi chinensis Sonn.) accessions from different germplasm collections using microsatellite markers, Tree Genet. Genomes, 9(2): 387-396 https://doi.org/10.1007/s11295-012-0560-1

Mao C.L., Pan Y.Z., and Gong X., 2009, A new Michelia cultivar 'Wanchun hanxiao', Yuanyi Xuebao (Acta Horticulturae Sinica), $36(5)$ : 778

Meng A.P., Wang H.C., Li J.Q., and Sima Y.K., 2006, A karyomorphological study of 40 species in 11 genera of the Magnoliaceae from China, Zhiwu Fenlei Xuebao (Acta Phytotaxonomica Sinica), 44(1): 47-63 https://doi.org/10.1360/aps040092

Ou D., Fan J.F., Zhou Y.X., and Gao J.S., 2017, Construction of fingerprint and analysis of genetic difference for hybrid clones of populous deltoides $\times$ section lacamahaca using SSR marker, Xibei Linxueyuan Xuebao (Journal of Northwest Forestry University), 32(2): 112-116

Pollegioni P., Woeste K., Mugnozza G.S., and Malvolti M.E., 2009, Retrospective identification of hybridogenic walnut plants by SSR fingerprinting and parentage analysis, Mol. Breeding, 24(4): 321-335 https://doi.org/10.1007/s11032-009-9294-7

Shen J.L., Bai T.D., Chen Y.B., Wang X.X., and Xu L.A., 2015, The fingerprints construction of clones in Pinus massoniana seed orchard, Fenzi Zhiwu Yuzhong (Molecular Plant Breeding), 13(3): 646-652

Song S., Huang Y.Z., Dong L.M., Huang Y.J., Zeng Y.R., and Wu Z.M., 2012, Simple sequence repeat (SSR) markers in Carya cathayensis, Zhejiang Nonglin Daxue Xuebao (Journal of Zhejiang A\&F University), 29(4): 626-633

Sun W.B., and Zhou J., 2004, A new proposal on generic division of the Magnoliaceae, Yunnan Zhiwu Yanjiu (Acta Botanica Yunnanica), 26(2): 139-147

Sun X.C., Wang J.R., Dai L., Zhao J., and Liu M.J., 2015, Fertility of male-sterile germplasms under controlled hybridization and molecular identification of hybrids by SSR in Chinese jujube, Hebei Nongye Daxue Xuebao (Jounal of Agricultural University of Hebei), 38(5): 40-43

Sun Y., Liu Y.F.,Wang J., Guo Y., and Huang H.W., 2010, Ten polymorphic microsatellite markers in Michelia maudiae (Magnoliaceae), Am. J. Bot., 97(12): e157-e158

https://doi.org/10.3732/ajb.1000332

PMid:21616838

Ueno S., Aoki K., and Tsumura Y., 2009, Generation of expressed sequence tags and development of microsatellite markers for Castanopsis sieboldii var. sieboldii (Fagaceae), Ann. Forest Sci., 66(5): 509 https://doi.org/10.1051/forest/2009037

Wang G.Y., Shen Y.T., Jia H.X., Jiao Y., Chai C.Y., Bao J.S., Sun D.L., Jia H.J., and Gao Z.S., 2015, Construction of acrossing population between two Chinese bayberry cultivars 'Biqi' and 'Dongkui' and hybrid identification by polymorphic SSRs, Guoshu Xuebao (Journal of Fruit Science), 32(4 ): 555-560

Wang Q.M., Ye Y.Y., Ma J.W., Zhang Y.P., Chen Q.Y., and Zhang Y., 2016, Establishment of EST-SSR fingerprint for the major cultivars of Peach in Chengdu plain, Fenzi Zhiwu Yuzhong (Molecular Plant Breeding), 14(3): 638-646

Wang X.X., Zhou Q., Tao Y.Y., Xu M., Yu W.W., and Xu L.A., 2017, The fingerprints construction and genetic diversity analysis of 48 fruit used Ginkgo cultivars based on SSR markers, Fenzi Zhiwu Yuzhong (Molecular Plant Breeding), 15(5): 1963-1970

Wen Q., Song X.C., Tian J., Xiao F.M., and Jiang X.M., 2014, Molecular identification of new cultivated varieties in Michelia crassipes and the relationship analysis with four relative Michelia species, Fenzi Zhiwu Yuzhong (Molecular Plant Breeding), 12(3): 509-516

Wu X.T., Wen Y.F., Han W.J., Zhou H., and Xu G.B., 2016, Establishment of microsatellite marker genotyping technology by multiplex PCR with fluorescently labelled universal primers and application on Chinese fir (Cunninghamia lanceolata), Fenzi Zhiwu Yuzhong (Molecular Plant Breeding), 14(7): 1795-1803

Xu M., Li H.G., and Zhang B., 2006, Fifteen polymorphic simple sequence repeat markers from expressed sequence tags of Liriodendron tulipifera, Mol. Ecol. Res., 6(3): $728-730$ https://doi.org/10.1111/j.1471-8286.2006.01323.x

Yadav H.K., Ranjan A., Asif M.H., Mantri S., Sawant S.V., and Tuli R., 2011, EST-derived SSR markers in Jatropha curcas L.: development, characterization, polymorphism, and transferability across the species/genera, Tree Genet. Genomes, 7(1): 207-219 https://doi.org/10.1007/s11295-010-0326-6

Yang A.H., Zhang J.J., Tian H., and Yao X.H., 2012, Characterization of 39 novel EST-SSR markers for liriodendron tulipifera and cross-species amplification in L. chinense (Magnoliaceae), Am. J. Bot., 99(11): e460-e464

https://doi.org/10.3732/ajb.1200154

PMid:23108462

Ye C.X., Jiang J.Y., Dong P., Zhuang Z.G., Chen Q.L., and Xie Z.M., 2015, Genetic diversity and construction of fingerprint of Tamarix chinensis in the tarim river basin based on SSR analysis, Fenzi Zhiwu Yuzhong (Molecular Plant Breeding), 13(11): 2566-2571

Ye X.L., Hu X.M., and Zhou K.F., 2013, Reproductive technology study and application of Michelia Linn., Anhui Nongxue Tongbao (Anhui Agricultural Science Bulletin), 19(13): 35-36, 60

Zhang X.H., 2007, Advances in research of Michelia Linn., Guangxi Zhiwu (Guihaia), 27 (5): 712-719

Zhou W.C., Wen Q., Yang J., Wang J.W., Xu L.A., and Xu L.C., 2017, Establishment of DNA fingerprints and cluster analysis for oil camellia cultivars based on SSR markers, Fenzi ZhiwuYuzhong (Molecular Plant Breeding), 15(1): 238-249 